\title{
Rabbits (Oryctolagus cuniculus) as a Model System for Longitudinal Experimental Opioid Treatments: Implications for Orthopedic and Biomedical Research
}

\author{
Janna M. Andronowski ${ }^{1, *}{ }^{\mathbb{D}}$, Adam J. Schuller ${ }^{2}$, Mary E. Cole ${ }^{3} \oplus$, Abigail R. LaMarca ${ }^{4}$, Reed A. Davis ${ }^{4}$ \\ and Gina R. Tubo ${ }^{5}$ iD \\ 1 Division of BioMedical Sciences, Faculty of Medicine, Memorial University of Newfoundland, \\ St. John's, NL A1B 3V6, Canada \\ 2 Department of Community and Environmental Health, Boise State University, Environmental Research Building, \\ 1295 W University Drive, Boise, ID 83706, USA; adamschuller@boisestate.edu \\ 3 Skeletal Biology Research Laboratory, Injury Biomechanics Research Center, The Ohio State University, \\ 2063 Graves Hall, Columbus, OH 43210, USA; Mary.Cole@osumc.edu \\ 4 Department of Biology, The University of Akron, 235 Carroll Street, Akron, OH 44325, USA; \\ ar199@uakron.edu (A.R.L.); rad115@uakron.edu (R.A.D.) \\ 5 College of Medicine, Northeast Ohio Medical University, 4209 State Route 44, Rootstown, OH 44272, USA; \\ gtubo@neomed.edu \\ * Correspondence: jandronowski@mun.ca
}

\section{check for}

updates

Citation: Andronowski, J.M.; Schuller, A.J.; Cole, M.E.; LaMarca,

A.R.; Davis, R.A.; Tubo, G.R. Rabbits (Oryctolagus cuniculus) as a Model System for Longitudinal

Experimental Opioid Treatments: Implications for Orthopedic and Biomedical Research. Osteology 2021, 1, 225-237. https://doi.org/10.3390/ osteology1040021

Academic Editor: Redha Taiar

Received: 26 September 2021

Accepted: 15 November 2021

Published: 18 November 2021

Publisher's Note: MDPI stays neutral with regard to jurisdictional claims in published maps and institutional affiliations.

Copyright: (c) 2021 by the authors. Licensee MDPI, Basel, Switzerland. This article is an open access article distributed under the terms and conditions of the Creative Commons Attribution (CC BY) license (https:// creativecommons.org/licenses/by/ $4.0 /)$.

\begin{abstract}
Due to the high prevalence of opioid prescription following orthopedic procedures, there is a growing need to establish an animal model system to evaluate the effects of opioids on bone remodeling. Rabbits have been employed as model organisms in orthopedic research as they exhibit well-defined cortical bone remodeling similar to humans. Existing research in rabbits has been limited to modes of opioid administration that are short-acting and require repeated application. Here, we present data from a proof-of-principle longitudinal study employing two opioid analgesic administration routes (subcutaneous injection and transdermal patch) to evaluate the efficacy of studying chronic opioid exposure in a rabbit model. Skeletally mature male New Zealand White rabbits (Oryctolagus cuniculus) were divided into three groups of seven animals: morphine, fentanyl, and control. Experimental treatments were conducted for eight weeks. Preparation of the skin at the fentanyl patch site and subsequent patch removal presented experimental difficulties including consistent skin erythema. Though noninvasive, the patches further caused acute stress in fentanyl animals. We conclude that though transdermal fentanyl patches may be preferred in an acute clinical setting, this method is not feasible as a means of long-term pain relief or opioid delivery in a laboratory context.
\end{abstract}

Keywords: transdermal fentanyl patch; opioid; rabbit; analgesia; bone remodeling

\section{Introduction}

Each year, over $70 \%$ of the 500,000 drug-related deaths worldwide are categorized as opioid-related [1]. In the United States, drug overdoses remain the leading cause of death for Americans under age 50 [2] with 21.7 deaths recorded per 100,000 people in 2017 [3]. In 2019, a record-high spike of opioid overdose deaths in the United States was recorded at nearly 50,000, with 73 percent involving synthetic opioids [4].

The prevalence of opioid use is due, in part, to developed dependence following legal prescription. Orthopedic surgeons are the third highest prescribers of opioids in the United States [5]. Orthopedic surgeons further account for an estimated $8.8 \%$ of acquired chronic opioid dependence following surgery [5]. In this sector of healthcare, morphine is a common treatment for post-operative pain following total joint arthroplasty [6]. In addition to morphine, transdermal fentanyl application has been shown to provide substantial levels 
for chronic pain management. Three meta-analyses demonstrated reduced side effects with transdermal fentanyl compared to sustained release oral-morphine [7-9]. Although efficacious in providing post-operative analgesia, a more recent review highlighted the detrimental effects with prolonged opioid exposure [10]. Pre-operative opioid use has been linked to negative post-operative outcomes, including the need for early total knee arthroplasty revision [11]. Not only is premature revision often required, but pre-operative opioid abuse may further lead to reduced effectiveness of opioid-induced analgesia following total joint arthroplasty [12].

Despite being commonly prescribed following orthopedic procedures, the overall effect of opioids at the cellular level of cortical bone remains understudied. Characterization of subcellular events requires the application of histological techniques that prevent analyses in living patients. This necessitates the use of animal models which mimic human bone remodeling in a controlled, reproducible environment. Previous researchers have explored the effects of opioid administration in small rodents, primarily to elucidate the impact of opioids on central neural pathways [13-16]. Domestic New Zealand White (NZW) rabbits (Oryctolagus cuniculus), however, demonstrate the potential to more accurately model human cortical bone dynamics [17]. Comparable to humans, rabbits display spontaneous cortical bone remodeling, whereas smaller laboratory animals (e.g., rodents) retain primary canals throughout their lives and exhibit little to no cortical bone remodeling [17-20]. As such, rabbits have been employed as a model organism in orthopedic research, including post-operative infection [21-23], orthopedic implants [24-27], and joint injury [28-33].

Despite well-documented use of opioids for post-operative pain in orthopedic procedures, and the extensive use of rabbits in orthopedic relevant research, the potential impact of opioid exposure on rabbit behavior and health remains understudied. Previous work has examined the effect of observer presence on rabbit behavior in a post-operative setting using morphine and tramadol hydrochloride as analgesics [34]. Other research has evaluated the use of fentanyl transdermal patch application in post-operative pain management in rabbits $[35,36]$. These studies, however, do not assess rabbit behavior and the efficacy of the transdermal delivery system over time. To that end, we present data from a longitudinal proof-of-principle study assessing the practicality of transdermal patches for rabbits in long-term opioid exposure experiments. Our overarching objectives were to (1) demonstrate the long-term use of injectable morphine sulfate and transdermal fentanyl patches in a rabbit model system, (2) examine the behavior of rabbits exposed to extended opioid regimens, and (3) test the hypothesis that NZW rabbits are an appropriate animal model system for studying the prolonged effects of opioid exposure on bone turnover for use in orthopedic comparative medicine.

\section{Materials and Methods}

A detailed animal protocol (18-11-12 ARC) was approved by The University of Akron Institutional Animal Care and Use Committee (IACUC). All research team members completed in-person training with The University of Akron Research Vivarium (UARV) attending veterinarian in proper ethical care, handling, euthanasia, and use of laboratory animals.

\subsection{Animals}

Skeletally mature, healthy, 6-month-old (2.3-3.0 kg), male NZW rabbits (Oryctolagus cuniculus; $n=21$ ) were acquired from Covance Research Products Inc. (Denver, PA, USA). Rabbits were individually housed in stainless steel rabbit batteries with perforated plastic floor inserts that allowed for limited visual interaction between animals, while keeping the animals lodged separately. Rabbits were fed Harlan Teklad Global High Fiber Rabbit Diet (Envigo, Madison, WI, USA) (150 g/day) and water was provided ad libitum by way of hard plastic water bottles. Enrichment foods (e.g., spinach, dried fruits, papaya tablets) were provided daily, and enrichment devices (e.g., rattles, jingle balls, flexi-keys) were provided in rabbit batteries and exercise pens and changed weekly. Rabbits were placed in floor-based exercise pens three times weekly for a $45 \mathrm{~min}$ period to allow for normal 
postural changes (e.g., hindlimb stretching, running). The housing room was maintained at $61^{\circ} \mathrm{F}$ to $70^{\circ} \mathrm{F}\left(16^{\circ} \mathrm{C}\right.$ to $\left.21^{\circ} \mathrm{C}\right)$, at $30 \%$ to $70 \%$ humidity, and on a $12: 12 / \mathrm{h}$ light:dark cycle. The rabbits were quarantined and habituated to the testing conditions for a two-week period prior to experimental treatments.

\subsection{Experimental Design}

Using a random number generator, the rabbits were divided into three groups of seven animals each: morphine, fentanyl, and controls. The control group was further randomly divided into saline vehicle $(n=3)$ and transdermal sham patch groups $(n=4)$. These group sizes were based on the mean numbers employed in previous characterizations of this model for cancellous bone or cortical geometry/density [37-41]. After the acclimation period, experimental treatments were applied to control and opioid groups (morphine and fentanyl) for eight weeks. The proposed opioid dosing levels are consistent with clinical recommendations for analgesia in rabbits and were finalized with the UARV veterinarian. Drug dose was calculated based on individual rabbit weight $(\mathrm{kg})$, measured at the start of each week. The morphine sulfate group received a dose of $3 \mathrm{mg} / \mathrm{kg} /$ day via subcutaneous bolus injection. The saline vehicle control group was administered saline at a dose of $3 \mathrm{mg} / \mathrm{kg}$ /day also via subcutaneous injection.

Transdermal fentanyl patches acted as a slow-release delivery agent and reduced the dosing frequency from daily to every third day. The dorsum of each fentanyl-group rabbit was shaved to remove fur, and a $25 \mu \mathrm{g} / \mathrm{h}$ slow-release transdermal fentanyl patch (Henry Schein Inc., Melville, NY, USA) was placed on the interscapular region, according to the manufacturer's instructions. Patch size and specific dosage were selected based on data obtained by Foley et al. [42] and Jain et al. [35] The patches were affixed via adhesives associated with the patch manufacturing. Patches were further secured by applying a medical-grade Tegaderm ${ }^{\mathrm{TM}}$ (3M, Maplewood, MN, USA) transparent film dressing, used in clinical settings to cover IV insertion sites and burns. A $2 \%$ isopropyl myristate softening solution was applied to the skin of control patch animals and placebo patches Tegaderm $^{\mathrm{TM}}$ transparent film dressing) [43]. Rabbit jackets (Lomir Biomedical, Malone, NY, USA) were used to cover fentanyl and control transdermal patches (Tegaderm ${ }^{\mathrm{TM}}$ ) to prevent the animals from chewing, removing, or ingesting these from the interscapular region.

\subsection{Data Collection}

Daily observations were recorded and scored at consistent time points throughout the experiment. These records detailed normalcy, or acute changes, in fecal output, food consumption, appearance, and behavior. All animals were weighed weekly.

\subsection{Statistical Analysis}

Statistical analyses were performed in R version 3.6.1 (5 July 2019) (The R Foundation for Statistical Computing). To analyze statistical differences between drug treatment groups, fecal output (normal, slightly low, low, very low) and food consumption levels (full, moderate, low) were coded numerically. Jacket use (yes/no) was also coded numerically for use as a covariate. Analysis was restricted to the experimental drug treatment period, following acclimation.

\section{Results}

Fecal output was numerically coded as Normal $=1$, Slightly Low $=2$, Low $=3$, and Very Low $=4$ following comparable fecal output scoring descriptions as outlined in Weaver et al. [44]. Food consumption was numerically coded as Full =1, Moderate $=2$, and Low $=3$. Mean fecal output per animal decreased from fentanyl (mean $=1.24, \mathrm{SD}=0.305)$ to control $($ mean $=1.26, \mathrm{SD}=0.216)$ to morphine groups $($ mean $=1.33, \mathrm{SD}=0.151)$. Mean food consumption per animal decreased from control (mean $=1.32, \mathrm{SD}=0.204$ ) to fentanyl $($ mean $=1.49, \mathrm{SD}=0.362)$ to morphine groups $($ mean $=1.81, \mathrm{SD}=0.251)$. 
Non-jacketed animals included all morphine group rabbits $(n=7)$ and saline control group rabbits $(n=3)$. Non-jacketed animals had lower mean fecal output (mean $=1.33$, $\mathrm{SD}=0.283$ ) than jacketed animals (mean $=1.23, \mathrm{SD}=0.152$ ). Similarly, non-jacketed animals had lower mean food consumption (mean $=1.68, \mathrm{SD}=0.382$ ) than jacketed animals (mean $=1.41, \mathrm{SD}=0.249$ ). These trends may reflect the lowest fecal output and food consumption of morphine group rabbits, which comprise $70 \%$ of non-jacketed animals.

Graphic representation of food consumption and fecal output (Figure 1) suggested that these two variables were correlated. Pearson's correlations were used, as a ShapiroWilk test indicated that all drug groups were normally distributed in both mean fecal output (Control: $\mathrm{W}=0.928, p=0.532$; Morphine: $\mathrm{W}=0.865, p=0.167$; Fentanyl: $\mathrm{W}=0.905$, $p=0.365$ ) and mean food consumption (Control: $\mathrm{W}=0.910, p=0.394$; Morphine: $\mathrm{W}=0.927$, $p=0.527$; Fentanyl: $\mathrm{W}=0.913, p=0.420$ ). Fecal output and food consumption were strongly $(\mathrm{r}=0.5-1.0)$ and significantly $(p<0.05)$ correlated for all drug groups (Control: $\mathrm{r}=0.821$, $p=0.034$; Morphine: $\mathrm{r}=0.901, p=0.006$; Fentanyl: $\mathrm{r}=0.857, p=0.024$ ).

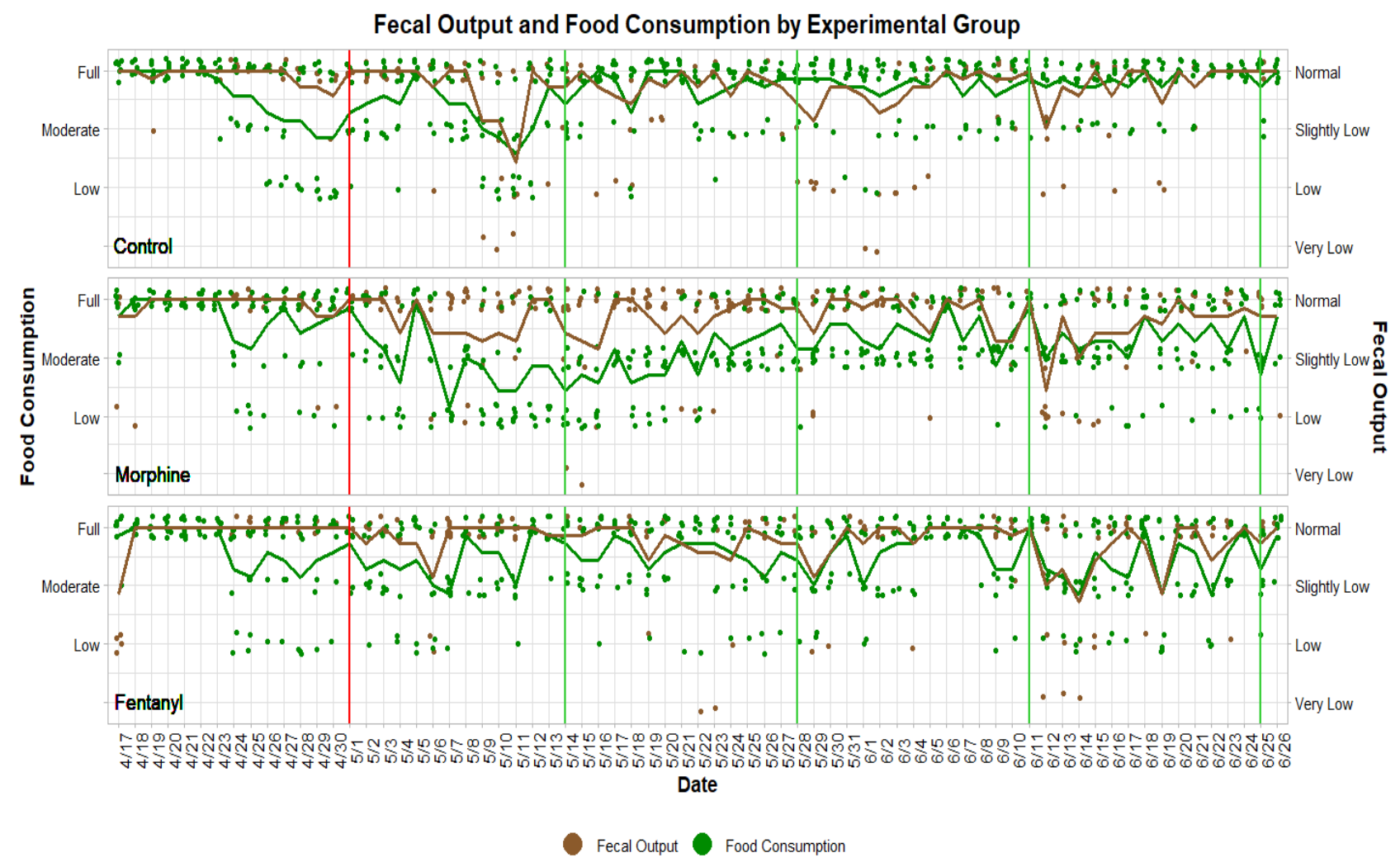

Figure 1. Correlation between mean food consumption (solid green line) and mean fecal output (solid brown line). Data points indicate food consumption (green) and fecal output (brown) for individual animals. Study timepoints include drug treatment initiation (red vertical line) and subsequent calcein injections (green vertical lines). For morphine rabbits, mean food consumption is depressed relative to mean fecal output between the drug treatment start date and the third injection.

A one-way ANCOVA indicated that fecal output was not significantly impacted by either the main effect of drug treatment group $(\mathrm{F}(2,17)=0.286, p=0.755, \eta \mathrm{p} 2=0.033$, power $=0.095)$ or the co-variate of jacketing $(F(1,17)=0.451, p=0.767, \eta p 2=0.511$, power $=0.103$ ). ANCOVA was suitable for this analysis as a Shapiro-Wilk test indicated that residuals were normally distributed $(\mathrm{W}=0.930, p=0.211)$. A Levene's test confirmed homogeneity of variances $(\mathrm{F}=0.877, p=0.433)$.

The main effect of drug treatment group did have a significant effect on food consumption, as indicated by a one-way ANCOVA $(\mathrm{F}(2,17)=5.441, p=0.0149, \eta p 2=0.390$, power $=0.841)$. A retrospective power analysis confirmed that our drug treatment group size $(n=7)$ exceeds the per-group sample size $(n=6.14)$ needed to obtain the observed 
effect size (Cohen's $\mathrm{f}=0.8$ ) at the recommended 0.80 power. Mean food consumption followed the pattern Control > Fentanyl > Morphine. Post-hoc analyses with Tukey's HSD indicated that differences in mean food consumption reached statistical significance only for the Control $>$ Morphine pairwise comparison $(p=0.012)$. Food consumption did not significantly differ between control and fentanyl groups $(p=0.501)$ or fentanyl and morphine groups $(p=0.118)$. The co-variate of jacketing had no significant effect on food consumption $(\mathrm{F}(1,17)=0.177, p=0.680, \eta \mathrm{p} 2=0.010$, power $=0.07)($ Figure 2$)$.
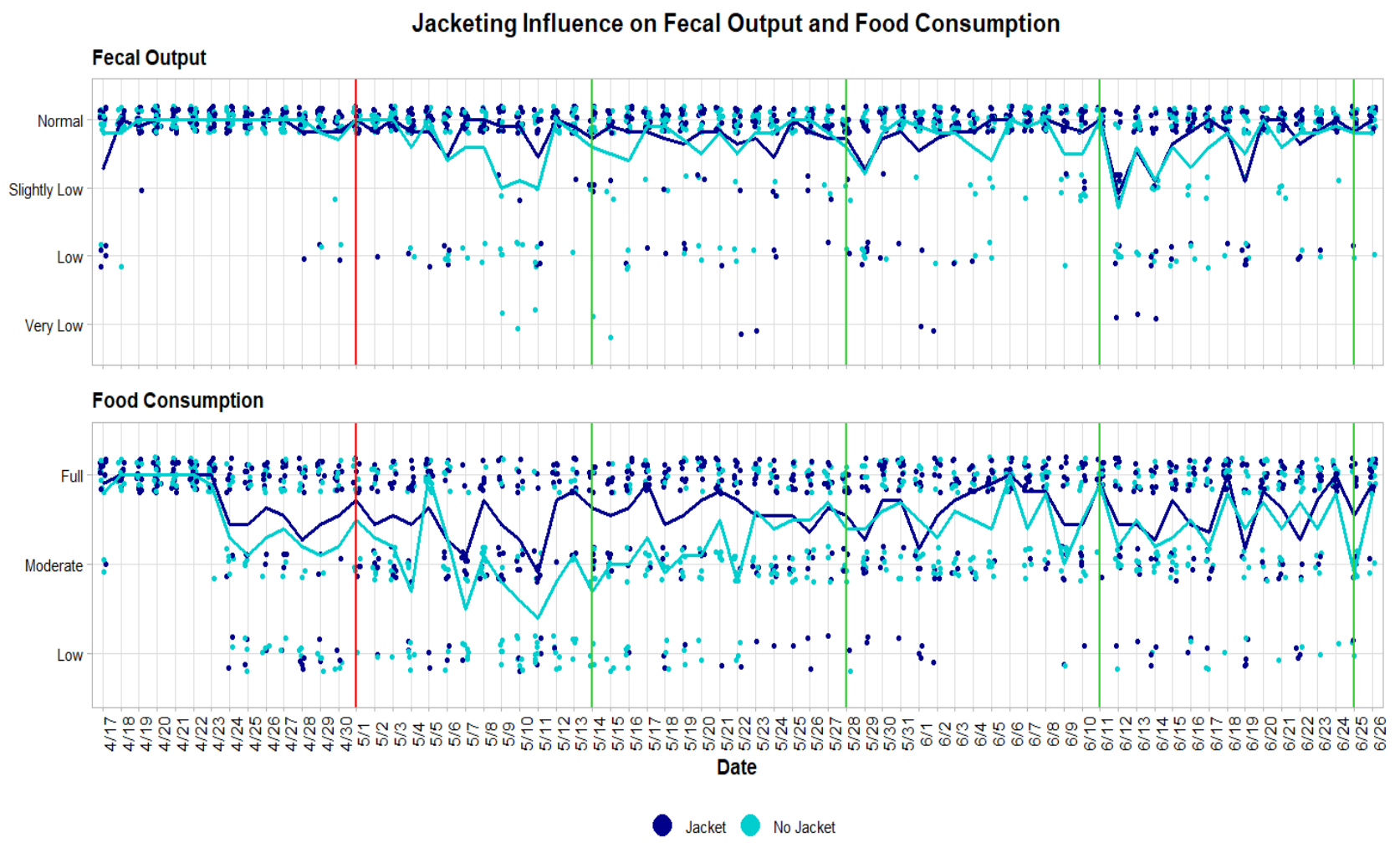

Figure 2. Non-significant differences between jacketed (dark blue) and non-jacketed (light blue) animals in both fecal output and food consumption. Study timepoints include drug treatment initiation (red vertical line) and subsequent calcein injections (green vertical lines).

ANCOVA was suitable for this analysis as a Shapiro-Wilk test indicated that residuals were normally distributed $(\mathrm{W}=0.958, p=0.474)$ and a Levene's test confirmed homogeneity of variances $(\mathrm{F}=1.611, p=0.227)$. The injection route of analgesic administration further appeared less stressful for the animals qualitatively when compared to fentanyl rabbits. Yet, the morphine sulfate injections consistently resulted in severe sedation within the first hour following dosing.

\section{Discussion}

Here, we provide a novel longitudinal perspective on opioid delivery in a rabbit animal model via transdermal fentanyl patch application for experimental research. Prior studies have reported limited concomitant effects of short-term use. Foley and colleagues [42] evaluated the efficacy of transdermal fentanyl patch administration in NZW rabbits. Animals were treated with fentanyl patches for one patch application cycle (72-h). Skin irritation was noted by the authors [42]; however, it was largely attributed to shaving the animals' fur for patch application. More recently, Mirschberger and colleagues [36] examined the use of transdermal fentanyl patches in rabbits on three different patch locations in the context of post-operative pain management. Their group reported that the neck and outer ear surface were the best options for transdermal patch placement. Their experimental period was $120-\mathrm{h}$ and the authors reported associated erythema and animals attempting patch 
removal. Ultimately, the authors concluded that transdermal patches are an acute and effective delivery route for pharmacologic analgesics. Additionally, Jain and colleagues [35] examined how opioid administration delays recovery and bone healing following spinal fusion surgery in a rabbit model. In this study, animals were treated with transdermal fentanyl patches for 10 weeks (four weeks pre-operatively and six weeks post-operatively). No information was reported regarding subject skin condition in relation to treatment with transdermal fentanyl patches. Although transdermal fentanyl patches have been documented as an effective pain relief agent in such clinical settings, we report novel side effects correlated with prolonged use which have implications for efficacy in the laboratory setting.

\subsection{Skin Irritation Resulting from Prolonged Patch Application}

Long-term transdermal fentanyl patch treatment presented several qualitative challenges for overall rabbit health and experimental facilitation by lab personnel. Specifically, rabbit chewing, and removal of transdermal patches had to be countered with patch re-application, telemetry jackets, and VetWrap ${ }^{\mathrm{TM}}$ (3M, Maplewood, MN, USA; Figure 3). Grooming restrictions and excessive chewing behaviors were imposed by the coverings. These limitations, combined with a strong adhesive associated with the fentanyl patches, resulted in notably irritated, flaky, and bruised patch application sites compared to the other groups (Figure 4). Surrounding fur was further matted and compressed (Figure 5).

While transdermal patches did not require daily application, this mode of drug delivery incited the need for daily patch checks and preventative measures to counter chewing behavior and skin irritation. Initially following patch application, certain rabbits began chewing the patch and dressings, and exhibited marked grooming surrounding the associated skin and fur. Fentanyl group rabbits were more commonly observed displaying such behaviors, compared to control group rabbits with only Tegaderm ${ }^{\mathrm{TM}}$ patch treatment. This difference may be due to the increased adhesive residue left behind by the fentanyl patch, or a differential behavioral response associated with opioid delivery.

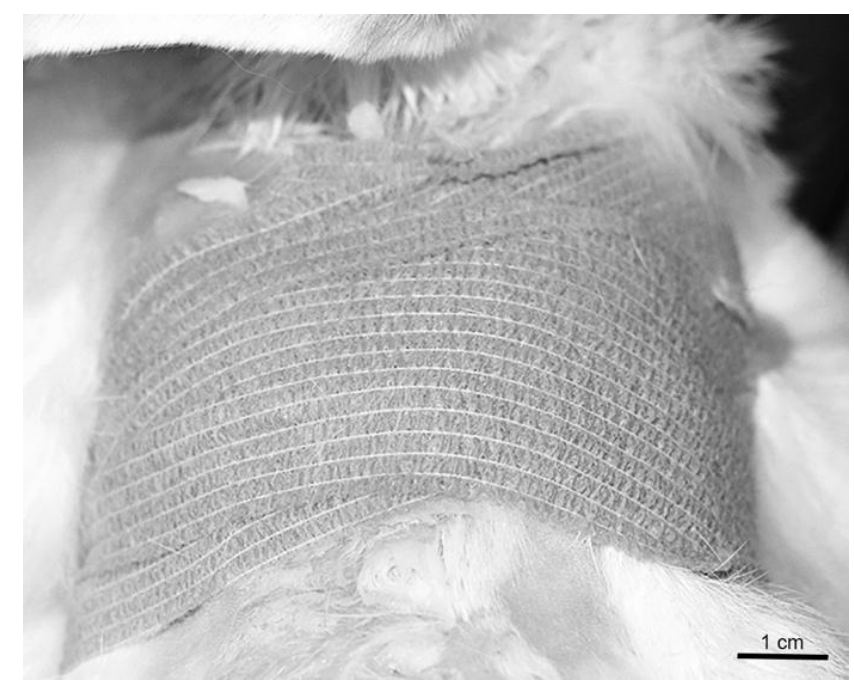

Figure 3. Fentanyl patch rabbit with applied VetWrap ${ }^{\mathrm{TM}}$ to prevent treatment patch chewing and manipulation. 


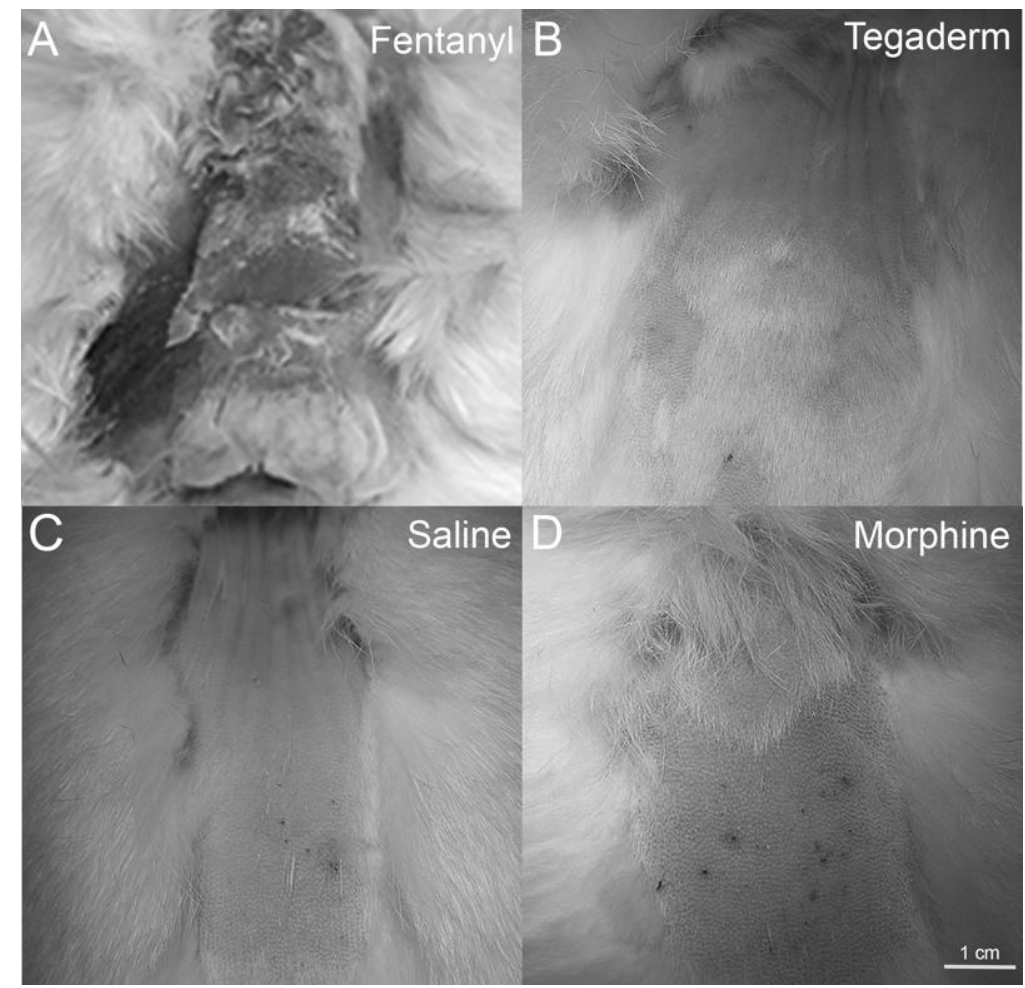

Figure 4. Representative images of skin irritation in each of the treatment groups. Transdermal fentanyl patch rabbit (A) displaying a contusion at a previous patch removal site, fur regrowth with adhesive residue, dry skin, and poor fur condition. Tegaderm ${ }^{\mathrm{TM}}$ control patch rabbit (B) showing fur regrowth and marked difference in quality of skin and fur condition. Saline control injection rabbit (C) with little fur regrowth, few injection site blemishes, and healthy fur condition. Morphine sulfate injection rabbit (D) displaying characteristic ' $\mathrm{V}$ ' shaped fur regrowth, injection site blemishes, and good overall fur condition.

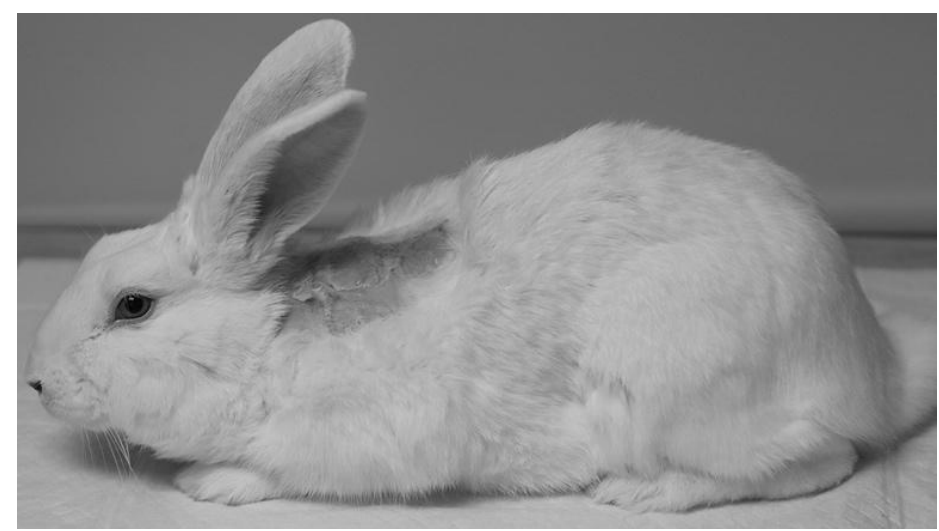

Figure 5. Fentanyl patch rabbit displaying poor overall fur quality resulting from grooming restrictions and excessive chewing behaviors from the placement of VetWrap ${ }^{\mathrm{TM}}$ and Lomir jackets to prevent the chewing and removal of the fentanyl patches.

To prevent chewing, all fentanyl and patch control rabbits were fitted with jacket coverings (Lomir Biomedical Inc.). The jackets fully covered the chest and back of the rabbit, and were secured with collars at the neck, shoulders, and hips. One rabbit in the fentanyl treatment group removed the jacket and ingested the opioid-containing patch from underneath the jacket. No long-term consequences were documented beyond an acute sedative effect. To prevent subsequent patch ingestion events, this rabbit was fitted with a pillow collar in addition to the jacket. Several other rabbits were able to partially 
unzip and remove the jackets on multiple occasions but did not attempt to remove or ingest the patch.

Jackets that rubbed against the patch application sites were observed to lift the Tegaderm $^{\mathrm{TM}}$ dressings and loosen the patches' adhesive edges. When jacket removal or patch loosening was observed, the back and chest of the rabbit were wrapped with VetWrap ${ }^{\mathrm{TM}}$ to prevent patch manipulation. Rabbits commonly attempted to pull the VetWrap ${ }^{\mathrm{TM}}$ from underneath the jacket and chew it open, with fentanyl rabbits spending significant portions of their observation time continually chewing/pulling the jackets and underlying VetWrap ${ }^{\mathrm{TM}}$. These behaviors required repeated replacement of jackets that were chewed beyond repair. By the study's end, patch presence and adherence needed to be checked daily, negating the time-saving qualities of applying a slow-release patch versus daily subcutaneous injection.

Additionally, fentanyl group rabbits commonly developed contusions or abrasions after a series of patch removal events (Figure 6). Compared to the Tegaderm ${ }^{\mathrm{TM}}$ dressing, the fentanyl patch adhered very tightly to the skin, and was difficult to remove when associated with adjacent fur or areas of new fur growth. Over the 72-h patch cycle, adhesive residue became tightly bound to the skin. These adhesive deposits could not be easily removed from bare skin and required the underlying hair follicles to grow out enough to allow for removal with clippers. Consequently, we typically adjusted patch placement immediately laterally, rostrally, or caudally to the original application site to avoid existing bruising, erythema, or adhesive buildup. Restraining an increasingly irritated rabbit was difficult and time-consuming during the process of patch removal, fur clipping, patch re-application, antibacterial ointment application to contusions, VetWrap ${ }^{\mathrm{TM}}$ application, and jacketing.

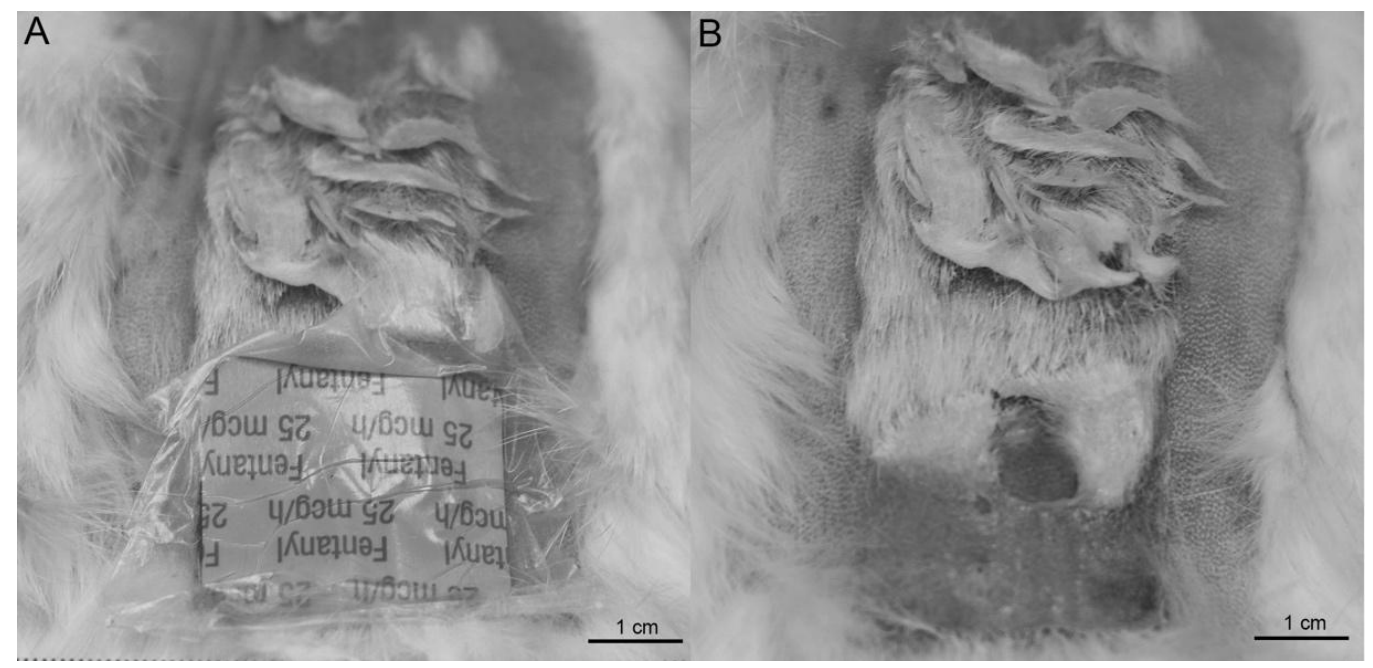

Figure 6. A representative example of skin irritation and contusions from prolonged use of transdermal fentanyl patch placement. (A) displays patch placement with Tegaderm ${ }^{\mathrm{TM}}$ covering applied. (B) shows the same animal with the fentanyl patch removed. Note the adhesive residue and matted fur from previous patch placement in the superior portion of both figures.

\subsection{Opioid Effects on Fecal Output and Food Consumption}

Analysis of fecal output revealed no significant influences from drug treatment or jacket use. The common side-effect of constipation from chronic opioid use [45] was not observed in morphine or fentanyl treatment groups, compared to controls. Food consumption was significantly impacted by the drug treatment, with morphine group rabbits consuming significantly less food on average than control or fentanyl group rabbits. Morphine group rabbits experienced a qualitative change in activity within the first hour after dosing, appearing sedated and sedentary, which was attributed to the subcutaneous delivery of the bolus. Since all rabbits were fed daily with base and enrichment foods following dosing, sedation during the initial delivery of new food may have reduced overall food consumption for morphine group rabbits. Fecal output and food consumption were 
strongly and significantly correlated. Control group and fentanyl group rabbits maintained this correlation throughout the study. Graphic visualization (Figure 1) indicated that morphine group rabbits dropped in mean food consumption, relative to mean fecal output, after the drug treatment start date. Mean food consumption, however, increased over this depressed period, suggesting that morphine group rabbits became acclimated to the sedative effect over the course of the study. Mean fecal output and food consumption are aligned for morphine group rabbits.

Although fentanyl group rabbits were acutely agitated by the application of jackets, collars, VetWrap ${ }^{\mathrm{TM}}(3 \mathrm{M})$, and tightly adhered patches, these devices did not significantly affect their food consumption or fecal output in comparison to controls. Notably, jacket use also had no significant effect on fecal output or food consumption across jacketed control and fentanyl group rabbits.

Certain animals across each opioid group presented with acute anorexia, which was associated with abnormally low fecal output. No direct causes of anorexia were identified apart from one rabbit who sustained a laceration of the lower gingiva and was treated with a chlorohexidine rinse. All animals exhibiting this trend regained normal gastrointestinal motility within one week of onset.

\subsection{Limitations}

Longitudinal blood collection was not conducted to assess plasma opioid concentration at different timepoints throughout the dosing period. Regular blood draws would have increased stress for the animals due to the employment of rabbit restrainers and were discouraged by attending veterinarians given the stress behaviors witnessed. This exclusion presents challenges for determining the circulating level of opioid in the blood of the animal. Consequently, the experimental dose was based on literature from preexisting studies where acute opioid delivery was assessed in similar rabbit models with established success [42]. In addition, our study did not employ quantitative measures for determining food consumption or fecal output (e.g., obtaining weights of these variables). Daily observations were performed and recorded, however, by a consistent technician team with extensive rabbit husbandry experience. These observations were further consistent with previously published scoring descriptions provided by Weaver et al. [44]. It is also important to note that animals may have obtained higher doses of opioids via subcutaneous injection due to difficulties with jacket compliance in the fentanyl group. As such, a promising area for future experimentation may involve the administration of opioids via osmotic pumps [46]. While likely not capable of spanning the longitudinal duration of this study, a revised administration route may prevent a low-maintenance alternative to slow-release transdermal patch application.

\subsection{Bone Remodeling and Transdermal Fentanyl Patches}

To better characterize the effects of chronic opioid use on bone remodeling, rabbits offer a promising model system as they are the smallest traditionally used laboratory animals with well-defined cortical remodeling [17]. As a result, rabbits have been used as experimental animals for studying central canal size and the vascular network of cortical bone $[18,19]$. Bone remodeling can be highly influenced by mechanical loading properties (including force strength, frequency, duration), resulting in increases in bone deposition [47]. While there are documented differences in mechanical loading properties following chronic opioid administration [48], it is critical to note that restrictions imposed via jackets, VetWrap ${ }^{\mathrm{TM}}$, and pillow collar can influence bone remodeling, as evidenced by behavioral changes in canine studies [49]. Thus, researchers must remain consistent in strategic interventions to prevent patch removal across treatment and control groups. It is possible that the extrapolation of these data to the context of the greater literature may result in inconsistencies for jacketed, patch administration animals. This evidence further supports our recommendation to refrain from using transdermal patches for longitudinal opioid delivery in a rabbit model in the context of bone research. 


\section{Conclusions}

Rabbits have served as model organisms to test the efficacy of prophylactic antibiotics following surgery [21-23], new biocompatible implants and hardware [24-28], and to mimic bone and tendon pathological states [28-32]. These studies highlight the benefit of the use of rabbits in comparative research to explore novel therapeutic methods in the orthopedic field. The literature, however, fails to consider the practical use of rabbits as a model organism when administered opioid analgesics. Although the use of transdermal fentanyl patches for rabbit analgesia may be preferred in an acute clinical setting, this delivery method is not feasible for long-term pain relief or opioid delivery in a laboratory context. In the current study, all animals subjected to transdermal fentanyl patch application consistently displayed erythema and continuously attempted to remove patches, which resulted in acute animal stress and an increased time commitment for lab personnel. In contrast, the morphine sulfate injection group did not demonstrate detrimental changes in fur appearance or overall health, though these animals consumed less food throughout the study. There were no significant effects of opioid administration on fecal output, with morphine group rabbits regaining normal correlation with food and fecal output for the last fourth of the experimental period. The observed sedative side-effects of the subcutaneous delivery of a larger opioid dose could have implications for individuals hoping to assess metabolic performance or other time-sensitive metrics. With the drawbacks associated with transdermal patch opioid administration, we suggest that orthopedic researchers employ an alternative administration route when conducting longitudinal opioid studies. In future work, we plan to evaluate the prolonged impact of longitudinal fentanyl administration via subcutaneous injection on bone turnover in a rabbit model system, while controlling for indirect confounding effects of opioid exposure including caloric intake, hormonal effects, and exercise regimens.

Author Contributions: Author contributions are as follows: (1) J.M.A.: Conceptualization; Project Design; Methodology; Acquisition of Data; Data Visualization; Data Analysis/Interpretation; Project Administration; Supervision; Writing-original draft; Critical Revision of Manuscript; Writing—review and editing; Approving Final Version of Manuscript. (2) A.J.S.: Methodology; Acquisition of Data; Writing—original draft; Critical Revision of Manuscript; Writing—review and editing; Approving Final Version of Manuscript. (3) M.E.C.: Acquisition of Data; Data Visualization; Figure Preparation; Data Analysis/Interpretation; Writing-original draft; Critical Revision of Manuscript; Writing-review and editing; Approving Final Version of Manuscript. (4) A.R.L.: Acquisition of Data; Writing—original draft; Writing - review and editing; Approving Final Version of Manuscript. (5) R.A.D.: Acquisition of Data; Data Visualization; Figure Preparation; Writing-original draft; Writing-review and editing; Approving Final Version of Manuscript. (6) G.R.T.: Acquisition of Data; Writing-original draft; Writing—review and editing; Approving Final Version of Manuscript. All authors have read and agreed to the published version of the manuscript.

Funding: This project is supported by Award No. 2018-DU-BX-0188, awarded by the National Institute of Justice, Office of Justice Programs, U.S. Department of Justice.

Institutional Review Board Statement: The study was conducted according to the guidelines of the Declaration of Helsinki and approved by the Institutional Animal Care and Use Committee (IACUC) of The University of Akron (18-11-12 ARC, 7 December 2018).

Informed Consent Statement: Not applicable.

Data Availability Statement: Not applicable.

Acknowledgments: The authors would like to thank The University of Akron Research Vivarium staff, specifically Beth Kenaga, for assistance with animal care. We further thank our consulting veterinarians Stanley Dannemiller and Lou Turchyn for their advice and veterinary care over the duration of the study. Special thanks also to J.T. Taylor, Z.H. Hume, P. Amira, H. Pupu, and P. Wess for thoughtful editing and critical review that improved the manuscript. 
Conflicts of Interest: The authors declare no conflict of interest. The funders had no role in the design of the study; in the collection, analyses, or interpretation of data; in the writing of the manuscript, or in the decision to publish the results. The opinions, findings, and conclusions or recommendations expressed in this publication are those of the author(s) and do not necessarily reflect those of the Department of Justice.

\section{References}

1. World Health Organization. Opioid Overdose. Available online: https://www.who.int/news-room/fact-sheets/detail/opioidoverdose (accessed on 18 July 2021).

2. Salmond, S.; Allread, V. A Population Health Approach to America's Opioid Epidemic. Orthop. Nurs. 2019, 38, 95-108. [CrossRef]

3. Hernandez, A.; Branscum, A.J.; Li, J.; MacKinnon, N.J.; Hincapie, A.L.; Cuadros, D.F. Epidemiological and geospatial profile of the prescription opioid crisis in Ohio, United States. Sci. Rep. 2020, 10, 4341. [CrossRef]

4. Center for Disease Control and Prevention: Drug Overdose Deaths. Available online: https://www.cdc.gov/drugoverdose/ data/statedeaths.html (accessed on 21 July 2021).

5. Morris, B.J.; Mir, H.R. The Opioid Epidemic: Impact on Orthopaedic Surgery. JAAOS—J. Am. Acad. Orthop. Surg. 2015, 23, 267-271. [CrossRef] [PubMed]

6. Allen, P.D.; Walman, T.; Concepcion, M.; Sheskey, M.; Patterson, M.K.; Cullen, D.; Covino, B.G. Epidural Morphine Provides Postoperative Pain Relief in Peripheral Vascular and Orthopedic Surgical Patients: A Dose-Response Study. Anesth. Analg. 1986, 65, 165-170. [PubMed]

7. Hadley, G.; Derry, S.; Moore, R.A.; Wiffen, P.J. Transdermal fentanyl for cancer pain. Cochrane Database Syst. Rev. 2013, 10, CD010270. [CrossRef]

8. Tassinari, D.; Sartori, S.; Tamburini, E.; Scarpi, E.; Raffaeli, W.; Tombesi, P.; Maltoni, M. Adverse Effects of Transdermal Opiates Treating Moderate-Severe Cancer Pain in Comparison to Long-Acting Morphine: A Meta-Analysis and Systematic Review of the Literature. J. Palliat. Med. 2008, 11, 492-501. [CrossRef] [PubMed]

9. Tassinari, D.; Sartori, S.; Tamburini, E.; Scarpi, E.; Tombesi, P.; Santelmo, C.; Maltoni, M. Transdermal fentanyl as a front-line approach to moderate-severe pain: A meta-analysis of randomized clinical trials. J. Palliat. Care 2009, 25, 172-180. [CrossRef] [PubMed]

10. Trasolini, N.A.; McKnight, B.M.; Dorr, L.D. The Opioid Crisis and the Orthopedic Surgeon. J. Arthroplast. 2018, 33, 3379-3382.e1. [CrossRef] [PubMed]

11. Ben-Ari, A.; Chansky, H.; Rozet, I. Preoperative Opioid Use Is Associated with Early Revision After Total Knee Arthroplasty: A Study of Male Patients Treated in the Veterans Affairs System. JBJS 2017, 99, 1-9. [CrossRef]

12. Goplen, C.M.; Verbeek, W.; Kang, S.H.; Jones, C.A.; Voaklander, D.C.; Churchill, T.A.; Beaupre, L.A. Preoperative opioid use is associated with worse patient outcomes after Total joint arthroplasty: A systematic review and meta-analysis. BMC Musculoskelet. Disord. 2019, 20, 234. [CrossRef]

13. Kiyatkin, E.A. Respiratory depression and brain hypoxia induced by opioid drugs: Morphine, oxycodone, heroin, and fentanyl. Neuropharmacology 2019, 151, 219-226. [CrossRef] [PubMed]

14. Bobeck, E.N.; Schoo, S.M.; Ingram, S.L.; Morgan, M.M. Lack of Antinociceptive Cross-Tolerance with Co-Administration of Morphine and Fentanyl into the Periaqueductal Gray of Male Sprague-Dawley Rats. J. Pain 2019, 20, 1040-1047. [CrossRef]

15. Zubrzycki, M.; Janecka, A.; Liebold, A.; Ziegler, M.; Zubrzycka, M. Effects of centrally administered endocannabinoids and opioids on orofacial pain perception in rats. Br. J. Pharmacol. 2017, 174, 3780-3789. [CrossRef] [PubMed]

16. Lefevre, E.M.; Pisansky, M.T.; Toddes, C.; Baruffaldi, F.; Pravetoni, M.; Tian, L.; Kono, T.J.Y.; Rothwell, P.E. Interruption of continuous opioid exposure exacerbates drug-evoked adaptations in the mesolimbic dopamine system. Neuropsychopharmacology 2020, 45, 1781-1792. [CrossRef] [PubMed]

17. Recker, R.R.; Kimmel, D.B.; Dempster, D.; Weinstein, R.S.; Wronski, T.J.; Burr, D.B. Issues in modern bone histomorphometry. Bone 2011, 49, 955-964. [CrossRef]

18. Pazzaglia, U.E.; Bonaspetti, G.; Rodella, L.F.; Ranchetti, F.; Azzola, F. Design, morphometry and development of the secondary osteonal system in the femoral shaft of the rabbit. J. Anat. 2007, 211, 303-312. [CrossRef] [PubMed]

19. Pazzaglia, U.E.; Congiu, T.; Raspanti, M.; Ranchetti, F.; Quacci, D. Anatomy of the Intracortical Canal System: Scanning Electron Microscopy Study in Rabbit Femur. Clin. Orthop. Relat. Res. 2009, 467, 2446-2456. [CrossRef]

20. Pazzaglia, U.E.; Zarattini, G.; Giacomini, D.; Rodella, L.; Menti, A.M.; Feltrin, G. Morphometric Analysis of the Canal System of Cortical Bone: An Experimental Study in the Rabbit Femur Carried Out with Standard Histology and Micro-CT. Anat. Histol. Embryol. 2010, 39, 17-26. [CrossRef]

21. Izakovicova, P.; Borens, O.; Trampuz, A. Periprosthetic joint infection: Current concepts and outlook. EFORT Open Rev. 2019, 4, 482-494. [CrossRef]

22. Bottagisio, M.; Coman, C.; Lovati, A.B.Y. 2019: Animal models of orthopaedic infections. A review of rabbit models used to induce long bone bacterial infections. J. Med. Microbiol. 2021, 68, 506-537. [CrossRef]

23. Chae, K.; Jang, W.Y.; Park, K.; Lee, J.; Kim, H.; Lee, K.; Lee, C.K.; Lee, Y.; Lee, S.H.; Seo, J. Antibacterial infection and immuneevasive coating for orthopedic implants. Sci. Adv. 2020, 6, eabb0025. [CrossRef] [PubMed] 
24. Radha, R.; Sreekanth, D. Insight of magnesium alloys and composites for orthopedic implant applications-A review. J. Magnes. Alloys 2017, 5, 286-312. [CrossRef]

25. Antoniac, I.; Adam, R.; Biță, A.; Miculescu, M.; Trante, O.; Petrescu, I.M.; Pogărășteanu, M. Comparative Assessment of In Vitro and In Vivo Biodegradation of Mg-1Ca Magnesium Alloys for Orthopedic Applications. Materials 2020, 14, 84. [CrossRef] [PubMed]

26. Gao, P.; Fan, B.; Yu, X.; Liu, W.; Wu, J.; Shi, L.; Yang, D.; Tan, L.; Wan, P.; Hao, Y.; et al. Biofunctional magnesium coated Ti6Al4V scaffold enhances osteogenesis and angiogenesis in vitro and in vivo for orthopedic application. Bioact. Mater. 2020, 5, 680-693. [CrossRef] [PubMed]

27. Feng, C.; Xue, J.; Yu, X.; Zhai, D.; Lin, R.; Zhang, M.; Xia, L.; Wang, X.; Yao, Q.; Chang, J.; et al. Co-inspired hydroxyapatite-based scaffolds for vascularized bone regeneration. Acta Biomater. 2021, 119, 419-431. [CrossRef] [PubMed]

28. Dai, Y.; Lu, J.; Li, F.; Yang, G.; Ji, G.; Wang, F. Changes in cartilage and subchondral bone in a growing rabbit experimental model of developmental trochlear dysplasia of the knee. Connect. Tissue Res. 2021, 62, 299-312. [CrossRef]

29. Zhang, W.; Zhou, H.; Feng, M.; Wang, B.; Su, Q.; Li, J. Assessment of whether the rabbit subscapularis tendon model is suitable for studying the human chronic rotator cuff pathology: Discovery of a new ligament connecting the glenoid and subscapularis tendon. Acta Orthop. Traumatol. Turc. 2020, 54, 497-501. [CrossRef] [PubMed]

30. Hirose, T.; Mae, T.; Ishibashi, Y.; Suzuki, T.; Ohori, T.; Murase, T.; Nakata, K. Comparison of tendon-bone healing between a newly developed ultrasound device and the conventional metallic drill in a rabbit MCL reconstruction model. J. Orthop. Sci. 2021, 26, 908-914. [CrossRef]

31. Huang, K.; Cai, H.; Zhang, P.; Wu, L. Comparison between two rabbit models of posttraumatic osteoarthritis: A longitudinal tear in the medial meniscus and anterior cruciate ligament transection. J. Orthop. Res. 2020, 38, 2721-2730. [CrossRef]

32. Li, Y.; Feng, R.; Liu, X.; Wang, G.; Wang, W.; Lu, Q.; Huang, W.; Wu, H.; Cai, X. A Post-Traumatic Osteoarthritic Model of Hip Following Fracture of Acetabulum in Rabbit: A Preliminary Study by Macroscopic and Radiographic Assessment. Orthop. Surg. 2021, 13, 296-305. [CrossRef]

33. Liu, X.; Chen, R.; Jiang, L.; Li, X.; Sun, Z. Effect of infusion irrigation with different irrigating solutions on transient receptor potential vanilloid 5 and intra-articular inflammation in a post-traumatic osteoarthritis rabbit model. Eur. J. Med. Res. 2021, 26, 24 [CrossRef]

34. Pinho, R.H.; Leach, M.C.; Minto, B.W.; Rocha, F.D.L.; Luna, S.P.L. Postoperative pain behaviours in rabbits following orthopaedic surgery and effect of observer presence. PLOS ONE. 2020, 15, e0240605. [CrossRef]

35. Jain, N.; Himed, K.; Toth, J.M.; Briley, K.C.; Phillips, F.M.; Khan, S.N. Opioids delay healing of spinal fusion: A rabbit posterolateral lumbar fusion model. Spine J. 2018, 18, 1659-1668. [CrossRef] [PubMed]

36. Mirschberger, V.; von Deimling, C.; Heider, A.; Spadavecchia, C.; Rohrbach, H.; Zeiter, S. Fentanyl Plasma Concentrations after Application of a Transdermal Patch in Three Different Locations to Refine Postoperative Pain Management in Rabbits. Animals 2020, 10, 1778. [CrossRef] [PubMed]

37. Baofeng, L.; Zhi, Y.; Bei, C.; Guolin, M.; Qingshui, Y.; Jian, L. Characterization of a rabbit osteoporosis model induced by ovariectomy and glucocorticoid. Acta Orthop. 2010, 81, 396-401. [CrossRef]

38. Castañeda, S.; Calvo, E.; Largo, R.; González-González, R.; de la Piedra, C.; Díaz-Curiel, M.; Herrero-Beaumont, G. Characterization of a new experimental model of osteoporosis in rabbits. J. Bone Miner. Metab. 2008, 26, 53-59. [CrossRef] [PubMed]

39. Castañeda, S.; Largo, R.; Calvo, E.; Rodríguez-Salvanés, F.; Marcos, M.E.; Díaz-Curiel, M.; Herrero-Beaumont, G. Bone mineral measurements of subchondral and trabecular bone in healthy and osteoporotic rabbits. Skelet. Radiol. 2006, 35, 34-41. [CrossRef] [PubMed]

40. Liu, X.; Lei, W.; Wu, Z.; Cui, Y.; Han, B.; Fu, S.; Jiang, C. Effects of glucocorticoid on BMD, micro-architecture and biomechanics of cancellous and cortical bone mass in OVX rabbits. Med. Eng. Phys. 2011, 34, 2-8. [CrossRef] [PubMed]

41. Wen, X.-X.; Xu, C.; Wang, F.-Q.; Feng, Y.-F.; Zhao, X.; Yan, Y.-B.; Lei, W. Temporal Changes of Microarchitectural and Mechanical Parameters of Cancellous Bone in the Osteoporotic Rabbit. BioMed Res. Int. 2015, 2015, 263434. [CrossRef] [PubMed]

42. Foley, P.L.; Henderson, A.L.; Bissonette, E.A.; Wimer, G.R.; Feldman, S.H. Evaluation of Fentanyl Transdermal Patches in Rabbits: Blood Concentrations and Physiologic Response. Comp. Med. 2001, 51, 239-244. [PubMed]

43. Moore, J. Final Report on the Safety Assessment of Myristyl Myristate and Isopropyl Myristate. J. Am. Coll. Toxicol. 1982, 1, 55-80. [CrossRef]

44. Weaver, L.A.; Blaze, C.A.; Linder, D.E.; Andrutis, K.A.; Karas, A.Z. A Model for Clinical Evaluation of Perioperative Analgesia in Rabbits (Oryctolagus Cuniculus). J. Am. Assoc. Lab. Anim. Sci. JAALAS 2010, 49, 845-851.

45. Jeal, W.; Benfield, P. Transdermal fentanyl. A review of its pharmacological properties and therapeutic efficacy in pain control. Drugs 1997, 53, 109-138. [CrossRef] [PubMed]

46. Perry, C.R.; Rice, S.; Ritterbusch, J.K.; Burdge, R.E. Local administration of antibiotics with an implantable osmotic pump. Clin. Orthop. Relat. Res. 1985, 192, 284-290. [CrossRef]

47. Du, J.; Yang, J.; He, Z.; Cui, J.; Yang, Y.; Xu, M.; Qu, X.; Zhao, N.; Yan, M.; Li, H.; et al. Osteoblast and Osteoclast Activity Affect Bone Remodeling Upon Regulation by Mechanical Loading-Induced Leukemia Inhibitory Factor Expression in Osteocytes. Front. Mol. Biosci. 2020, 7, 347. [CrossRef] 
48. Coluzzi, F.; Scerpa, M.S.; Centanni, M. The Effect of Opiates on Bone Formation and Bone Healing. Curr. Osteoporos. Rep. 2020, 18, 325-335. [CrossRef] [PubMed]

49. Shenoda, Y.; Ward, M.P.; McKeegan, D.; Fawcett, A. "The Cone of Shame": Welfare Implications of Elizabethan Collar Use on Dogs and Cats as Reported by their Owners. Animals 2020, 10, 333. [CrossRef] 